Article

\title{
Electrothermal Averaged Model of a Diode-Transistor Switch Including IGBT and a Rapid Switching Diode
}

\author{
Paweł Górecki and Krzysztof Górecki * \\ Department of Marine Electronics, Gdynia Maritime University, Morska 83, 81-225 Gdynia, Poland; \\ p.gorecki@we.umg.edu.pl \\ * Correspondence: k.gorecki@we.umg.edu.pl
}

Received: 18 May 2020; Accepted: 10 June 2020; Published: 12 June 2020

\begin{abstract}
This study proposes an electrothermal averaged model of the diode-transistor switch including insulated gate bipolar transistor (IGBT) and a rapid switching diode. The presented model has the form of subcircuits dedicated for simulation program with integrated circuit emphasis (SPICE) and it makes it possible to compute characteristics of DC-DC converters at the steady state considering self-heating phenomena, both in the diode and in IGBT. This kind of model allows computations of voltages, currents and internal temperatures of all used semiconductor devices at the steady state. The formulas used in this model are adequate for both: continuous conducting mode (CCM) and discontinuous conducting mode (DCM). Correctness of the proposed model is verified experimentally for a boost converter including IGBT. Good accuracy in modeling these converter characteristics is obtained.
\end{abstract}

Keywords: IGBT; DC-DC converter; electrothermal model; averaged model; thermal phenomena; self-heating; diode-transistor switch; power electronics

\section{Introduction}

Nowadays, power electronic circuits often include DC-DC converters [1-5]. Designing these converters requires reliable methods of computer simulations $[1,5,6]$. They enable selection of optimal components and operating conditions of the designed converter. For more than 50 years, many scientists have been working on methods and models that allow fast computations of waveforms of currents and voltages as well as AC and DC characteristics of power converters [5-8]. To provide simulations of electronic circuits using the formulated models it is necessary to use software dedicated to electronic circuits simulation. SPICE (simulation program with integrated circuit emphasis) is commonly used for this purpose $[5,6,8-10]$. Its main advantage is easy implementation of any compact model of electronic components and devices.

Due to the switching mode of operation of DC-DC converters, their characteristics can be obtained with the sequential analysis of transient processes only. Such analysis requires, as a rule, a long time-and may cause convergence problems of computations [11]. In order to shorten the time of this analysis, the averaged models of DC-DC converters were proposed [5,8,12-15]. These models make it possible to compute characteristics of circuits at the steady state using a DC sweep (DC analysis) $[5,8,16]$. This is one of the types of the standard analyses realized in SPICE. Typically, a DC analysis needs a short computation time. In averaged models, the average values of voltages in nodes and currents flowing through branches of considered circuits are used instead of the instantaneous values of these quantities.

It is assumed that averaged DC-DC converters models should be formulated in accordance with two steps of their activation in "on" and "off" phases of a switch. In the first step, the transistor is turned on, and simultaneously the diode is turned off. In the second step, the transistor is turned off 
and simultaneously the diode is turned on. The considered states of operation are described using two subcircuits which depend on each other. For both the mentioned steps of operation, equations describing currents flowing through capacitors and voltages on inductors are formulated. Next, these equations are averaged across period $\mathrm{T}$ and compared to zero. Finally, equations describing dependences between average values of currents and voltage at the steady state in the considered DC-DC converter are obtained [5,8].

Averaged models of DC-DC converters have been described in literature for many years [5,8,12-21]. They can be presented in different network forms and they can be used for: transient, AC and DC analysis [5,8]. They also enable obtaining small-signal frequency characteristics, steady-state voltage-current characteristics and waveforms of currents and voltages in considered converters.

As it can be seen, e.g., in $[5,8,16]$, in all single-inductor DC-DC converters a diode-transistor switch can be distinguished. In such a switch a diode and one kind of transistors (BJT, JFET, MOSFET or IGBT) are included. The structure of such a switch, including insulated gate bipolar transistor (IGBT) and a diode, is shown in Figure 1.

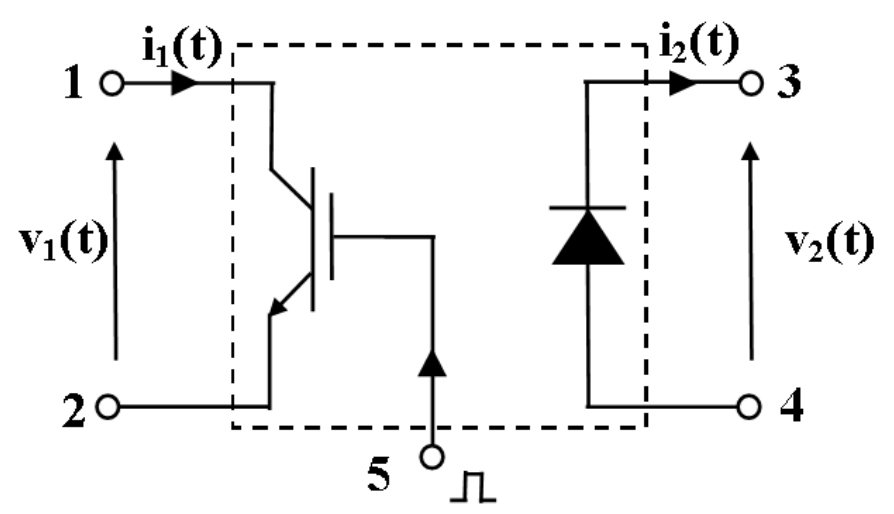

Figure 1. Diagram of a diode-transistor switch with IGBT and the diode.

The considered switch contains 5 terminals: 3 terminals of IGBT and 2 terminals of the diode. During operation of such a switch in any DC-DC converter, a control signal in the form of a rectangular pulses train is connected to terminal number 5 . The transistor and the diode are connected to other components of the considered DC-DC converter as shown in its diagram. Voltage between pairs of terminals 1, $2\left(\mathrm{v}_{1}(\mathrm{t})\right.$ voltage) and 3, $4\left(\mathrm{v}_{2}(\mathrm{t})\right.$ voltage) have the shape of rectangular pulses trains. At the steady state waveforms of voltages and currents are periodical.

In many papers, e.g., $[5,8,16,17,20,21]$ averaged models of a diode-transistor switch of different accuracy are described. In some of these models the diode and the transistor are described as ideal switches characterized by zero on-state resistance and infinite off-state resistance $[5,8]$. Another group of these models uses piecewise linear characteristics of the mentioned semiconductor devices $[5,8,16,17,21]$. Some of these models [21] take into account operation only in CCM (Continuous Current Mode), whereas models described in $[5,8,16]$ make it possible to compute characteristics of these converters operating both in CCM and DCM (Discontinuous Current Mode).

During operation of DC-DC converters self-heating phenomena occur in semiconductor devices contained in these converters $[11,16,17,22-24]$. The result of these phenomena is an increase in internal temperature of these devices and changes in the course of characteristics of these converters. As it is indicated, among others in [11,17], thermal phenomena occurring in components of low-voltage converters significantly influence characteristics of these converters. Thermal phenomena also strongly affect reliability of such converters, as presented in [11,16,17]. A computer analysis can be useful in estimating thermal phenomena. In order to apply such a method, an electro-thermal model of electronic components comprising a DC-DC converter is necessary.

In literature, averaged models of a diode-transistor switch containing ideal switches $[5,8,18,20]$ or MOSFETs $[16,17,25]$ are described. The model of a diode-transistor switch containing IGBT and 
a diode presented in the study [21] has a significantly simplified form. In the considered model, characteristics of the diode and IGBT are modeled using piecewise linear functions consisting of only two pieces. Such a manner of modeling DC characteristics of IGBT and a diode can cause a significant error of computations, especially in the range of low currents. Moreover, this model was verified only in the CCM. As it is pointed out in many papers $[5,8,16]$, omitting DCM can also constitute a cause of a significant error in computations. Finally, in the model presented in [21] thermal phenomena are not taken into account. The electrothermal averaged model of a diode-transistor switch including the power MOS transistor is described in [16,17]. Such models enable computations of voltages and currents in the considered converter and internal temperatures of semiconductor devices contained in the diode-transistor switch. Due to different shapes of output characteristics of IGBT and MOSFET operating in the on-state, the cited models are not adequate to analyze characteristics of DC-DC converters including IGBT and a diode.

In this study, the electrothermal averaged model of a diode-transistor switch including the IGBT is proposed. It is dedicated to electrothermal analysis of DC-DC converters containing such a switch and it makes it possible to compute values of current, voltage and internal temperatures of semiconductor devices contained in the mentioned switch. In electrothermal analyses, both electrical phenomena occurring in the analyzed DC-DC converter as well as self-heating phenomena occurring in both semiconductor devices are taken into account. In Section 2, the form of the elaborated model is presented. In Section 3, a manner of estimating model parameters is described and some results of modeling DC characteristics of components of the diode-transistor switch are shown. In Section 4, the results of usefulness of the elaborated model for determining characteristics of the boost converter are presented and discussed.

\section{Proposed Model}

The formulated electrothermal model of a diode-transistor switch is based on the concept described in the study $[16,17]$ for such a switch including the power MOS transistor. The network representation of the proposed electrothermal model of a diode-transistor switch (DTS) with IGBT and a diode is shown in Figure 2.

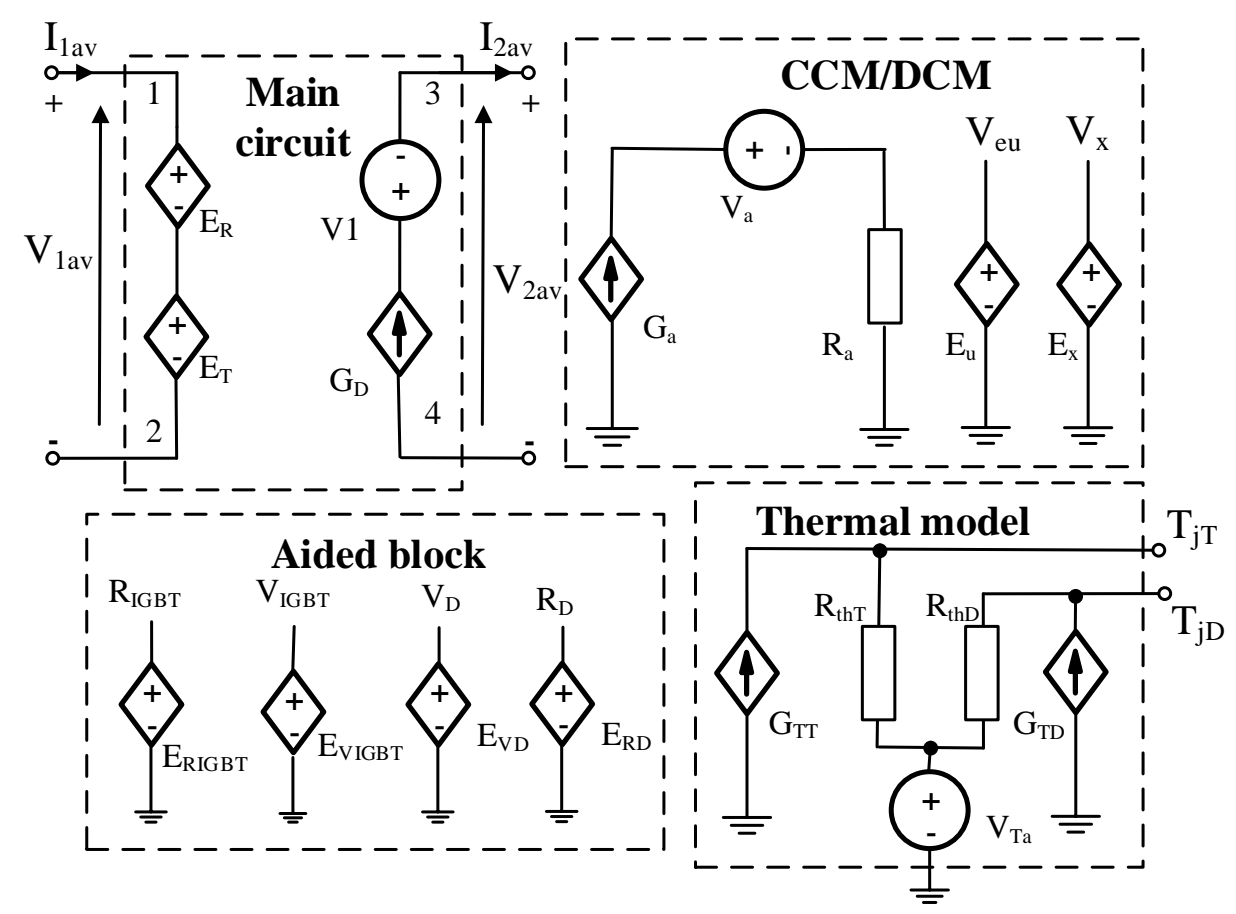

Figure 2. Network representation of the electrothermal averaged model of a diode-transistor switch (DTS) including IGBT and a diode. 
Terminals of the presented model denoted as 1, 2, 3 and 4 correspond to terminals of the real diode-transistor switch in the diagram shown in Figure 1. This model can be connected to other parts of the analyzed DC-DC converters through the mentioned terminals in accordance with the diagram of these converters. The control signal is not shown in the model, but frequency $\mathrm{f}$ and duty cycle $\mathrm{d}$ of this signal are parameters of the presented model that are used in descriptions of some controlled voltage and current sources existing in this model. The voltages on terminals $\mathrm{T}_{\mathrm{j} T}$ and $\mathrm{T}_{\mathrm{jD}}$ correspond to internal temperatures of IGBT and the diode, respectively.

The presented model consists of 4 blocks. These are: main circuit, aided block, thermal model and CCM/DCM. Blocks and all components contained in them are described below.

The main circuit includes two controlled voltage sources $E_{R}$ and $E_{T}$ modeling average voltage between output terminals of IGBT and controlled current source $G_{D}$ modeling the average value of diode current. Voltage source V1 of zero value is used to monitor the average value of diode current. Values of currents $I_{1} a v$ and $I_{2} a v$, as well as voltages $V_{1} a v$ and $V_{2} a v$ in the main circuit, are average values of diode and transistor voltages and currents. The connected in series controlled voltage sources $E_{R}$ and $E_{T}$ model a voltage drop between transistor output terminals. Controlled current source $G_{D}$ models diode current. The output values of these sources are described with elaborated formulas using the concept presented in the papers $[16,17]$. According to this concept, in each period of the control signal, current flows through the transistor for a time equal to $\mathrm{d} \cdot \mathrm{T}$, and through the diode-for a time equal to (1-d).T, wherein T is period of the control signal. Diode current-voltage characteristic and transistor output characteristic are described by piecewise linear functions. Parameters describing such piecewise linear functions depend on internal temperatures of the diode and IGBT. Values of these parameters are computed in the aided block, whereas internal temperatures of semiconductor devices are computed in the thermal model. The equivalent duty cycle $V_{e u}$, adequate for operation of the DC-DC converter containing the modeled diode-transistor switch, is computed in CCM/DCM block shown in Figure 2. The value of $V_{e u}$ depends on duty cycle and frequency of the control signal, inductance of the inductor contained in the analyzed DC-DC converter and output current of this converter.

Controlled voltage and current sources existing in the main circuit are described as follows

$$
\begin{gathered}
E_{T}=\frac{1-V_{e u}}{V_{e u}} \cdot\left(V_{2 a v}+V_{D}\right) \\
E_{R}=\frac{V_{I G B T}}{V_{e u}}+\frac{I_{1 a v} \cdot R_{I G B T}}{V_{e u}}+\frac{I_{1 a v} \cdot R_{D}}{V_{e u}^{2}} \cdot\left(1-V_{e u}\right) \\
G_{D}=\frac{1-V_{e u}}{V_{e u}} \cdot I_{1 a v}
\end{gathered}
$$

where current $I_{1 a v}$ and voltage $V_{2 a v}$ are denoted in Figure 2, $V_{e u}$ is voltage on controlled voltage source $E_{u}, V_{D}$ voltage and $R_{D}$ resistance are described by a piecewise linear characteristic of forward biased diode, whereas $V_{I G B T}$ voltage and resistance $R_{I G B T}$ are described by a piecewise linear output characteristic of switched-on IGBT. Parameters $V_{I G B T}, V_{D}, R_{D}$ and $R_{I G B T}$ depend on the device internal temperature ( $\mathrm{T}_{\mathrm{jT}}$ for IGBT and $\mathrm{T}_{\mathrm{j} D}$ for the diode) and on current flowing through these devices. Values of the mentioned parameters correspond to voltages on controlled voltage sources $\mathrm{E}_{\mathrm{VIGBT}}$, $\mathrm{E}_{\mathrm{VD}}, \mathrm{E}_{\mathrm{RD}}$ and $\mathrm{E}_{\mathrm{RIGBT}}$, respectively. These sources are included in the aided block. Descriptions of the mentioned parameters are as follows:

$$
V_{D}=\left\{\begin{array}{c}
V_{D 1} \cdot\left(1+\left(T_{j D}-T_{0}\right) \cdot \alpha_{V D 1}\right) \text { if } I_{2 a v}<a_{1} \\
V_{D 2} \cdot\left(1+\left(T_{j D}-T_{0}\right) \cdot \alpha_{V D 2}\right) \text { if } a_{1} \leq I_{2 a v}<a_{2} \\
V_{D 3} \cdot\left(1+\left(T_{j D}-T_{0}\right) \cdot \alpha_{V D 3}\right) \text { if } I_{2 a v} \geq a_{2}
\end{array}\right.
$$




$$
\begin{gathered}
R_{D}=\left\{\begin{array}{c}
R_{D 1} \cdot\left(1+\left(T_{j D}-T_{0}\right) \cdot \alpha_{R D 1}\right) \text { if } I_{2 a v}<a_{1} \\
R_{D 2} \cdot\left(1+\left(T_{j D}-T_{0}\right) \cdot \alpha_{R D 2}\right) \text { if } a_{1} \leq I_{2 a v}<a_{2} \\
R_{D 3} \cdot\left(1+\left(T_{j D}-T_{0}\right) \cdot \alpha_{R D 3}\right) \text { if } I_{2 a v} \geq a_{2}
\end{array}\right. \\
V_{I G B T}=\left\{\begin{array}{c}
V_{I G B T 1} \cdot\left(1+\left(T_{j T}-T_{0}\right) \cdot \alpha_{V I G B T 1}\right) \text { if } I_{1 a v}<b_{1} \\
V_{I G B T 2} \cdot\left(1+\left(T_{j T}-T_{0}\right) \cdot \alpha_{V I G B T 2}\right) \text { if } b_{1} \leq I_{1 a v}<b_{2} \\
V_{I G B T 3} \cdot\left(1+\left(T_{j T}-T_{0}\right) \cdot \alpha_{V I G B T 3}\right) \text { if } I_{1 a v} \geq b_{2}
\end{array}\right. \\
R_{I G B T}=\left\{\begin{array}{c}
R_{I G B T 1} \cdot\left(1+\left(T_{j T}-T_{0}\right) \cdot \alpha_{R I G B T 1}\right) \text { if } I_{1 a v}<b_{1} \\
R_{I G B T 2} \cdot\left(1+\left(T_{j T}-T_{0}\right) \cdot \alpha_{R I G B T 2}\right) \text { if } b_{1} \leq I_{1 a v}<b_{2} \\
R_{I G B T 3} \cdot\left(1+\left(T_{j T}-T_{0}\right) \cdot \alpha_{\text {RIGBT3 }}\right) \text { if } I_{1 a v} \geq b_{2}
\end{array}\right.
\end{gathered}
$$

In Equations (5) and (6) symbols $V_{D 1}, V_{D 2}, V_{D 3}, R_{D 1}, R_{D 2}, R_{D 3}, \alpha_{V D 1}, \alpha_{V D 2}, \alpha_{V D 3}, \alpha_{R D 1}, \alpha_{R D 2}$, $\alpha_{R D 3}, a_{1}$ and $a_{2}$ denote parameters of a piecewise linear model of diode DC characteristic. In turn, in Equations (6) and (7) symbols $V_{I G B T 1}, V_{I G B T 2}, V_{I G B T 3}, R_{I G B T 1}, R_{I G B T 2}, R_{I G B T 3}, \alpha_{V I G B T 1}, \alpha_{V I G B T 2}$, $\alpha_{V I G B T 3}, \alpha_{\text {RIGBT1 }}, \alpha_{\text {RIGBT2 }}, \alpha_{\text {RIGBT3 }}, b_{1}$ and $b_{2}$ denote parameters of a piecewise linear model of IGBT output characteristics. Values of temperatures $T_{j D}$ and $T_{j T}$ are computed in the thermal model, whereas $T_{0}$ represents reference temperature.

In the thermal model values of internal temperature of IGBT $\left(T_{j T}\right)$ and the diode $\left(T_{j D}\right)$ are computed with self-heating phenomena taken into account. The classical electrical analog of a DC compact thermal model described, e.g., in $[11,16,17,22,26,27]$ is used. In this analog temperature corresponds to voltage in selected nodes of this analog, whereas dissipated power is represented by current sources. The ability to remove heat generated in the diode and in IGBT is characterized by thermal resistance. In the proposed model voltage source $V_{T a}$ represents ambient temperature, resistors $R_{t h T}$ and $R_{t h D}$ denote thermal resistance of IGBT and the diode, respectively. Average values of power dissipated in the considered semiconductor devices are represented by controlled current sources $\mathrm{G}_{\mathrm{TT}}$ and $\mathrm{G}_{\mathrm{TD}}$. Currents flowing through these sources are described by the following formulas

$$
\begin{gathered}
G_{T D}=\left(V_{D}+\frac{R_{D} \cdot I_{2 a v}}{1-V_{e u}}\right) \cdot \frac{I_{2 a v}}{1-V_{e u}} \\
G_{T T}=\left(V_{I G B T}+\frac{R_{I G B T} \cdot I_{1 a v}}{V_{e u}}\right) \cdot \frac{I_{1 a v}}{V_{e u}}
\end{gathered}
$$

The proposed model can be used for computations of characteristics of DC-DC converters operating in CCM or DCM. In both mentioned modes of operation in each period of a control signal the transistor is turned on in time equal to the product of duty cycle $\mathrm{d}$ and period $\mathrm{T}$. In turn, the diode is turned on in time equal to (1-d). T in CCM and this time is shorter in DCM. In order to take into account influence of duty cycle $\mathrm{d}$, frequency $\mathrm{f}$ of the control signal and inductance $\mathrm{L}$ of the inductor included in the tested DC-DC converter on voltage $V_{e u}, \mathrm{CCM} / \mathrm{DCM}$ block is included in the model. This block includes controlled current source $G_{a}$, voltage source $V_{a}$ of zero value, resistor $R_{a}$ and controlled voltage sources $E_{u}$ and $E_{x}$.

Voltage $V_{e u}$ on voltage source $E_{u}$ is described by the formula

$$
V_{e u}=\left\{\begin{array}{c}
0 \text { if } V_{x}<0 \\
V_{x} \text { if } 0<V_{x}<1 \\
1 \text { if } V_{x}>1
\end{array}\right.
$$

where voltage $V_{x}$ on voltage source $E_{x}$ is described as follows

$$
V_{x}=\operatorname{LIMIT}\left(\operatorname{MAX}\left(d, \frac{d^{2}}{d^{2}+2 \cdot L \cdot f \cdot \frac{I_{V a}}{V_{2 a v}+V_{D}}}\right), 0,1\right)
$$


In Equation (11) LIMIT (.) and MAX (.) are SPICE standard functions described, e.g., in the book [28] and $I_{V a}$ denotes current flowing through controlled current source $G_{a}$ described with the formula of the form:

$$
G_{a}=\operatorname{MAX}\left(I_{1 a v}, 0\right)
$$

Resistor $R_{a}$ must be included in this block due to formal rules of SPICE. Voltage source $V_{a}$ is used to monitor the value of current $I_{V a}$.

\section{Estimation of Model Parameters}

Practical applications of the proposed model require estimation of parameter values existing in this model. For example, an estimate is performed for the IGBT of the type IGP06N60T [29] by Infineon Technologies and for the diode of the type IDP08E65 [30] by Infineon Technologies. Input data are characteristics of such devices measured by the authors with the use of the impulse method [31] and a source-meter Keithley 2612a [32] at different fixed values of ambient temperature. When these measurements are performed, the tested semiconductor devices are situated in a thermal chamber, in which the adjustable value of temperature can be obtained.

Values of the model parameters obtained by matching piecewise linear models of characteristics of the considered devices are given in Table 1.

Table 1. Values of parameters of the piecewise linear model of the used insulated gate bipolar transistor (IGBT) and diode.

\begin{tabular}{|c|c|c|c|c|c|c|c|}
\hline $\begin{array}{l}\text { Parameter Name } \\
\text { Parameter Value }\end{array}$ & $\begin{array}{c}\mathbf{V}_{\mathbf{D} 1}(\mathbf{V}) \\
0.63\end{array}$ & $\begin{array}{c}\mathbf{V}_{\mathbf{D} 2}(\mathbf{V}) \\
0.74\end{array}$ & $\begin{array}{c}\mathbf{V}_{\mathbf{D} 3}(\mathbf{V}) \\
0.847\end{array}$ & $\begin{array}{c}\alpha_{\mathbf{V D 1}}\left(\mathbf{K}^{-\mathbf{1}}\right) \\
-8.41 \times 10^{-3}\end{array}$ & $\begin{array}{c}\alpha_{\mathbf{V D 2}}\left(\mathbf{K}^{-\mathbf{1}}\right) \\
-3.92 \times 10^{-3}\end{array}$ & $\begin{array}{c}\alpha_{\mathbf{V D 3}}\left(\mathbf{K}^{-\mathbf{1}}\right) \\
-2.95 \times 10^{-3}\end{array}$ & $\begin{array}{c}\mathbf{a}_{1}(\mathbf{A}) \\
0.25\end{array}$ \\
\hline Parameter Name & $R_{D 1}(\Omega)$ & $R_{\mathrm{D} 2}(\Omega)$ & $R_{\mathrm{D} 3}(\Omega)$ & $\alpha_{\mathrm{RD} 1}\left(\mathrm{~K}^{-1}\right)$ & $\alpha_{\mathrm{RD} 2}\left(\mathrm{~K}^{-1}\right)$ & $\alpha_{\mathrm{RD} 3}\left(\mathrm{~K}^{-1}\right)$ & $a_{2}(A)$ \\
\hline Parameter Value & 0.75 & 0.191 & 0.1 & $4.67 \times 10^{-3}$ & $2.62 \times 10^{-3}$ & $1.74 \times 10^{-3}$ & 1.3 \\
\hline Parameter Name & $\mathrm{V}_{\text {IGBT1 }}(\mathrm{V})$ & $\mathrm{V}_{\text {IGBT2 }}(\mathrm{V})$ & $\mathrm{V}_{\text {IGBT3 }}(\mathrm{V})$ & $\alpha_{\text {VIGBT1 }}\left(K^{-1}\right)$ & $\alpha_{\text {VIGBT2 }}\left(K^{-1}\right)$ & $\alpha_{\text {VIGBT3 }}\left(K^{-1}\right)$ & $b_{1}(A)$ \\
\hline Parameter Value & 0.611 & 0.736 & 0.811 & $-3.04 \times 10^{-3}$ & $-1.63 \times 10^{-3}$ & $-1.2 \times 10^{-3}$ & 0.52 \\
\hline Parameter Name & $\mathrm{R}_{\mathrm{IGBT} 1}(\Omega)$ & $\mathrm{R}_{\mathrm{IGBT} 2}(\Omega)$ & $\mathrm{R}_{\text {IGBT3 }}(\Omega)$ & $\alpha_{\text {RIGBT1 }}\left(K^{-1}\right)$ & $\alpha_{\text {RIGBT2 }}\left(K^{-1}\right)$ & $\alpha_{\text {RIGBT3 }}\left(K^{-1}\right)$ & $b_{2}(A)$ \\
\hline Parameter Value & 0.443 & 0.195 & 0.127 & $3.61 \times 10^{-3}$ & $2.05 \times 10^{-3}$ & $1.9 \times 10^{-3}$ & 1.2 \\
\hline
\end{tabular}

In Figures 3 and 4 measured (points) and computed (lines) characteristics of the diode (Figure 3) and IGBT (Figure 4) are shown. These characteristics are measured and computed at selected values of ambient temperature $\mathrm{T}_{\mathrm{a}}$.

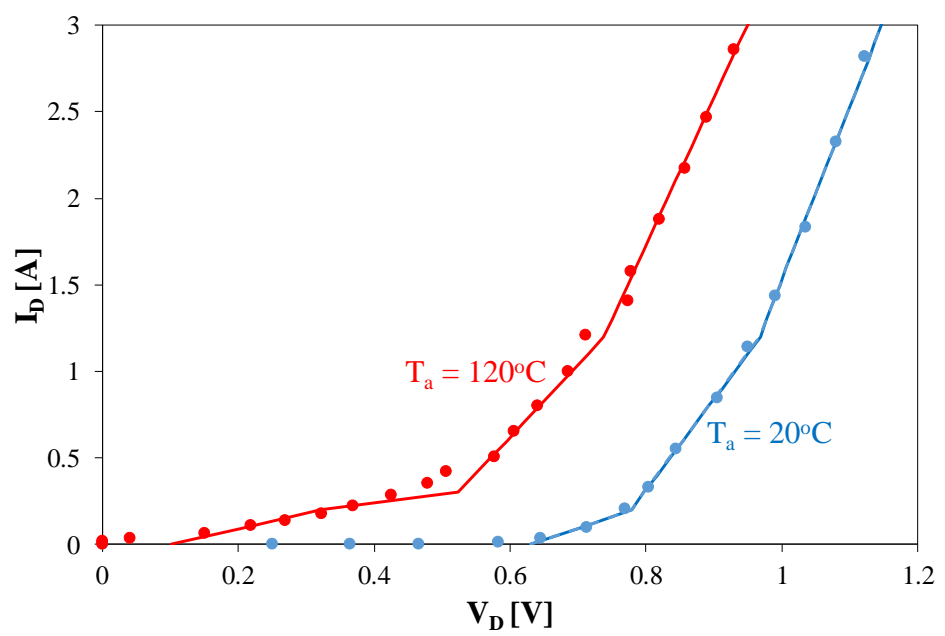

Figure 3. Characteristics of a forward-biased diode computed with the use of a piecewise linear model (lines) and measured (points) at selected values of temperature $\mathrm{T}_{\mathrm{a}}$. 


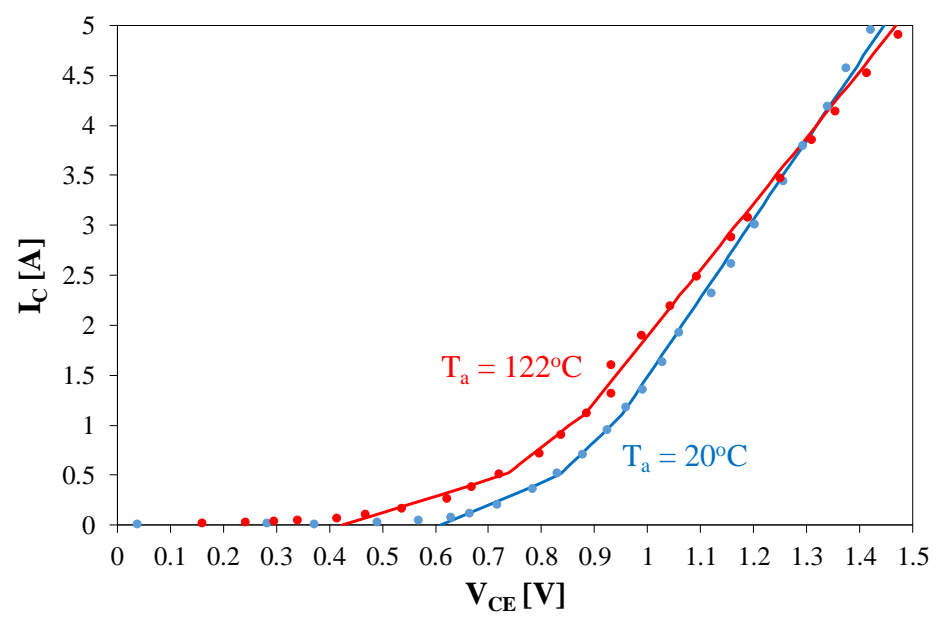

Figure 4. Output characteristics of insulated gate bipolar transistor (IGBT) computed with the use of a piecewise linear model (lines) and measured (points) at selected values of temperature $\mathrm{T}_{\mathrm{a}}$.

As is visible, the results of measurements and computations are convergent for both considered semiconductor devices in a wide range of changes of ambient temperature $\mathrm{T}_{\mathrm{a}}$. As can be observed, all characteristics are described using 4 line segments. A slope of the considered characteristics increases with an increase of the main current of the tested device. This means that series resistances of the diode and IGBT decrease with an increase of this current. It is also observed that the diode forward-voltage and on-voltage of IGBT at zero current decreases with an increase in ambient temperature.

With the diode, an increase in temperature causes a decrease in diode forward-voltage. In turn, for IGBT with a range of low collector current values, an increase in ambient temperature causes a decrease in on-voltage of IGBT. In contrast, for high collector current values, an increase in temperature $\mathrm{T}_{\mathrm{a}}$ causes an increase in on-voltage of IGBT.

The presented characteristics correspond to isothermal operating conditions of tested devices, at which self-heating phenomena can be omitted. In the real case, device internal temperature is higher than ambient temperature as a result of the mentioned phenomena $[26,27,33]$. The cooling conditions of this device are characterized by thermal resistance. This parameter is measured using impulse electrical methods described in [34-36].

Both considered semiconductor devices are situated in the TO-220 case. The measured values of IGBT and the diode are nearly the same and they are equal to about $44 \mathrm{~K} / \mathrm{W}$. Reference temperature $T_{0}$ is equal to $20^{\circ} \mathrm{C}$.

\section{Results of Measurements and Computations}

In order to verify usefulness of the proposed electrothermal averaged model of a diode-transistor switch, measurements and computations of characteristics of the boost converter with considered semiconductor devices were performed. A diagram of the tested converter is shown in Figure 5, whereas a photo of the tested converter is presented in Figure 6.

In the considered converter, the input voltage $V_{\text {in }}$ was equal to $12 \mathrm{~V}$, and $\mathrm{R}_{0}$ was load resistance. The inductance of inductor $L_{1}$ was equal to $560 \mu \mathrm{H}$ and capacitance of capacitor $C_{1}$ was equal to $1 \mathrm{mF}$. Voltage source $V_{\text {ctrl }}$ produced a rectangular pulsed train of frequency f equal to $10 \mathrm{kHz}$ and duty cycle d. Ammeters were used to measure the input and output currents of the tested converter. Internal resistance of these ammeters was equal to $0.31 \Omega$. The prototype was mounted on a PCB; the diode of the type IDP08E65 and IGBT of the type IGP06N60T operated without any heat-sinks. The control signal was given by a signal generator exciting gate driver IR2125 by Infineon Technologies.

Some waveforms of voltages and currents of the tested DC-DC converter were measured using an oscilloscope Rigol MS05104 and current probe Tektronix PCPA 300 for different parameters of the control signal and load resistances. For example, in Figure 7 measured waveforms of $v_{\mathrm{GE}}(\mathrm{t})$ 
voltage (yellow line), $\mathrm{v}_{\mathrm{CE}}(\mathrm{t})$ voltage (violet line) and $\mathrm{i}_{\mathrm{L}}(\mathrm{t})$ current (blue line) are shown. The mentioned quantities are marked in Figure 5 . Waveform of $i_{L}(t)$ was obtained after conversion of the measured current into voltage in the current probe. The conversion coefficient was equal to $1 \mathrm{~A} / \mathrm{V}$. During these measurements load resistance $R_{0}$ was equal to $47 \Omega$.

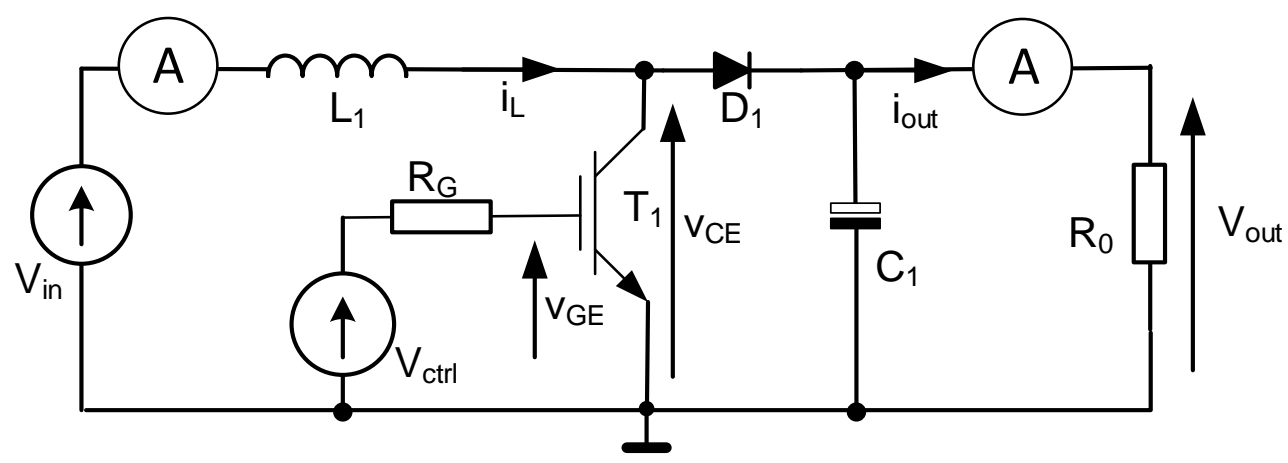

Figure 5. Diagram of the tested boost converter.

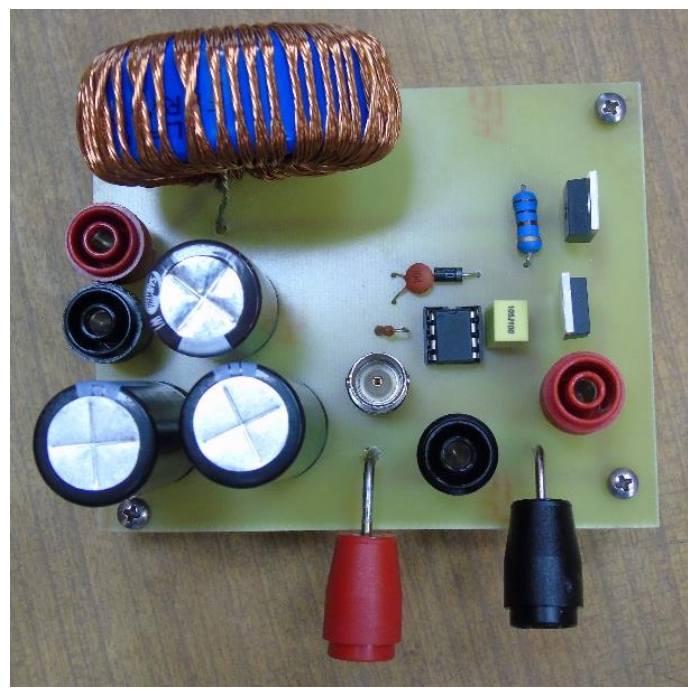

Figure 6. Photo of the tested boost converter.

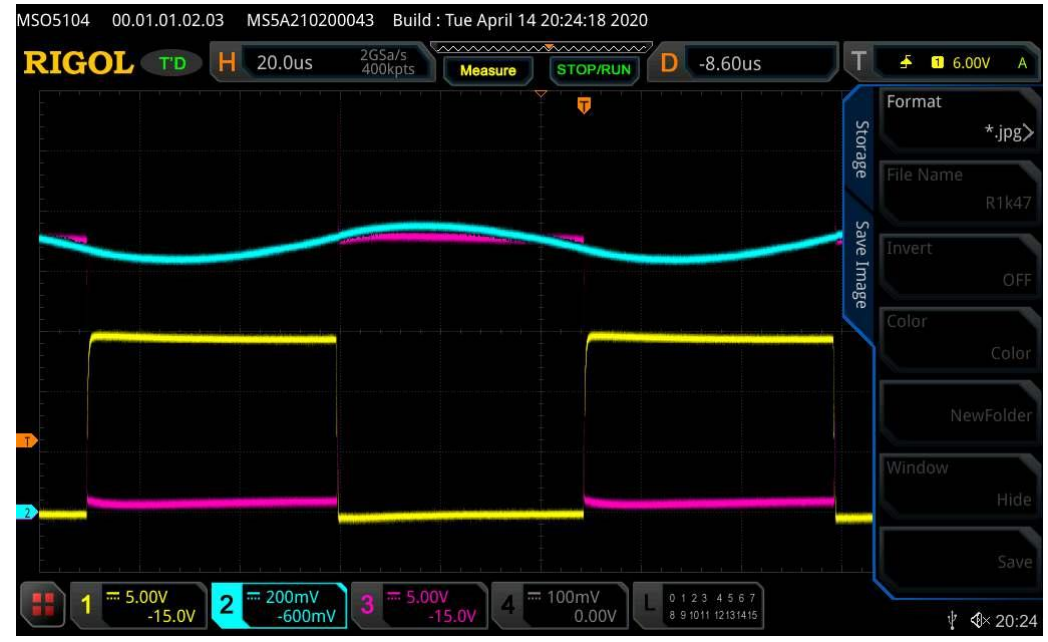

Figure 7. Measured waveforms of $v_{G E}(t)$ voltage, $v_{C E}(t)$ voltages and $i_{L}(t)$ current in the tested boost converter operating at load resistance $R_{0}=47 \Omega$. 
As it can be observed, the signal controlling the input of IGBT ( $\mathrm{v}_{\mathrm{GE}}$ voltage) had frequency equal to $10 \mathrm{kHz}$, duty cycle equal to 0.5 , low level voltage equal to zero and high level voltage equal to $15 \mathrm{~V}$. These parameters values of the control signal were adequate for the used transistor. The transistor output voltage $\mathrm{v}_{\mathrm{CE}}(\mathrm{t})$ had a shape of a rectangular pulsed train. The highest level of this voltage was equal to about $22 \mathrm{~V}$. The current $\mathrm{i}_{\mathrm{L}}(\mathrm{t})$ had positive values only, which proved that the tested converter operated in CCM.

It is important to notice that the tested DC-DC converter operated without any feedback loop, typically used in switch-mode power supplies including such converters. At the chosen operating condition, the influence of parameters of the control signal and on the load resistance were not compensated by the feedback loop. Therefore, any disadvantages of the proposed model can be clearly illustrated for the tested circuit.

Selected resulted of measurements and computations of the considered DC-DC converter are shown in the successive figures. In these figures points denote the results of measurements, solid lines-the results of computations performed with the use of the proposed electrothermal averaged model of a diode-transistor switch including IGBT and a rapid switching diode (called also the new model), black dashed lines-the results of computations performed with the use of the averaged model of a diode transistor switch with ideal switches described e.g., in $[5,8]$ and blue dotted lines-the results of computations performed with the use of the averaged model of a diode-transistor switch including IGBT described in [21].

Figures 8-11 present computed and measured characteristics of the considered converter operating at the fixed value of duty cycle $d=0.5$ and the varied value of load resistance $R_{0}$. In turn, Figures 12-15 show characteristics of this converter operating at the fixed value of load resistance $R_{0}=47 \Omega$ and the varied value of duty cycle $\mathrm{d}$. Values of voltages and currents were measured with the used of laboratory voltmeters and ammeters. The diode and transistor temperatures were measured with the use of an infrared method performed with a pyrometer PT-3S by Optex [37]. This instrument made it possible to measure the case temperature of the mentioned semiconductor devices. Due to a very small value of junction-case thermal resistance of the considered semiconductor devices-which was much lower than junction-ambient thermal resistance-a difference between internal and case temperatures of these devices was not higher than $5{ }^{\circ} \mathrm{C}$.

In Figure 8 measured and computed dependences of converter output voltage $V_{\text {out }}$ on load resistance $R_{0}$ are presented. As is visible, in the considered operating conditions, the boost converter operated in CCM for $R_{0}<100 \Omega$ and in DCM for $R_{0}>100 \Omega$. In both modes of operation, the new model guarantees good accuracy of computations. At small values of load resistance, a decrease was visible in the value of output voltage caused by influence of a voltage drop on the switched on transistor and diode. This voltage drop was an increasing function of converter output current and a decreasing function of load resistance $R_{0}$. Literature models described in $[5,8,21]$ could be used for the converter operating in CCM only, because differences between the results of computations performed with these models and the results of measurements were acceptable only in this mode. Of course, the results performed with the use of the model proposed in [21] were more convergent with the results of measurements in CCM than the results performed with the model given in [5,8].

Figure 9 presents dependences of watt-hour efficiency of the considered DC-DC converter on load resistance.

The obtained values of watt-hour efficiency were in the range from 0.8 to 0.9 . Values of this parameter computed using the electrothermal model differed from the results of measurements by no more than $7 \%$. The resulted obtained using the considered literature models were overstated even by $17 \%$.

In Figure 10 dependence of internal temperature of IGBT on load resistance was shown. Such dependence could be obtained with the use of the electrothermal model only. 


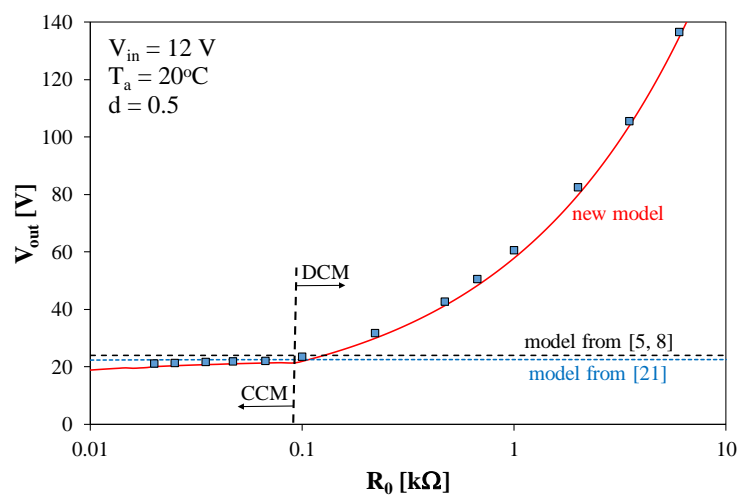

Figure 8. Computed and measured dependences of boost converter output voltage on load resistance.

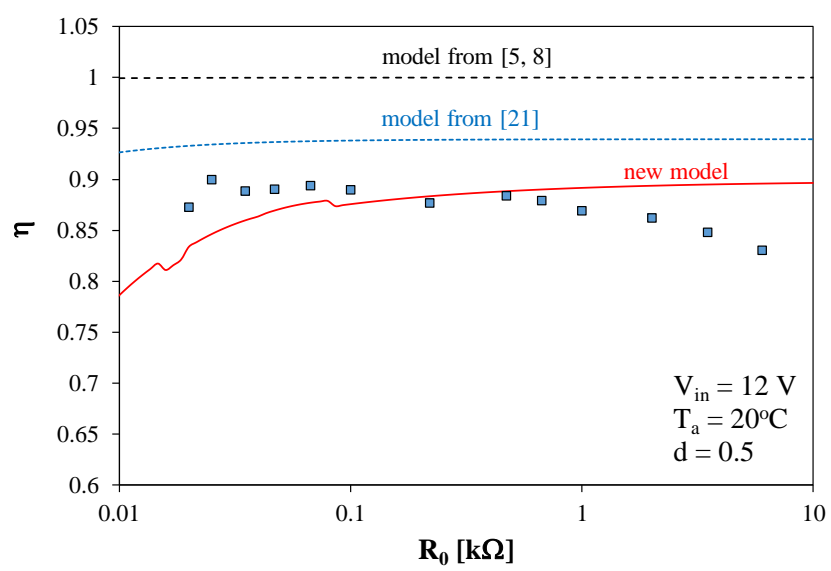

Figure 9. Computed and measured dependences of watt-hour efficiency of the boost converter on load resistance.

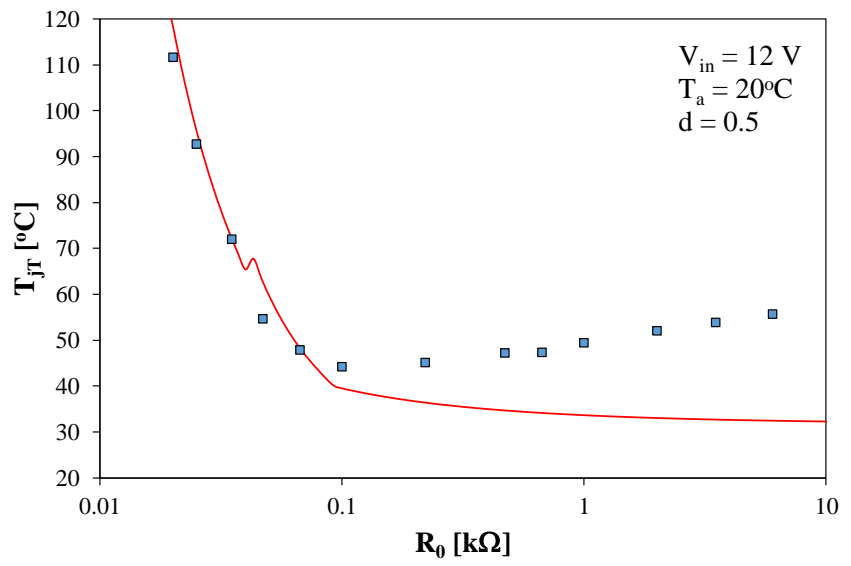

Figure 10. Computed and measured dependence of internal temperature of IGBT on load resistance. 


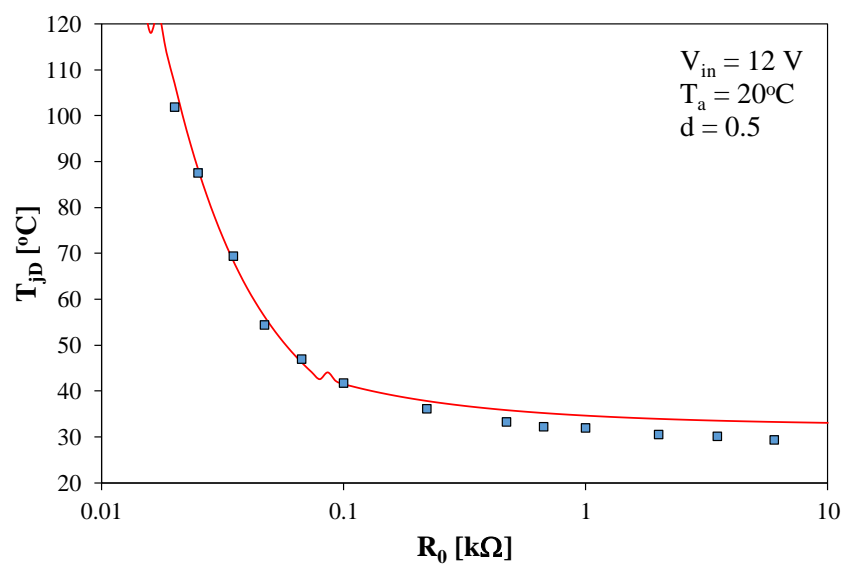

Figure 11. Computed and measured dependence of internal temperature of the diode on load resistance.

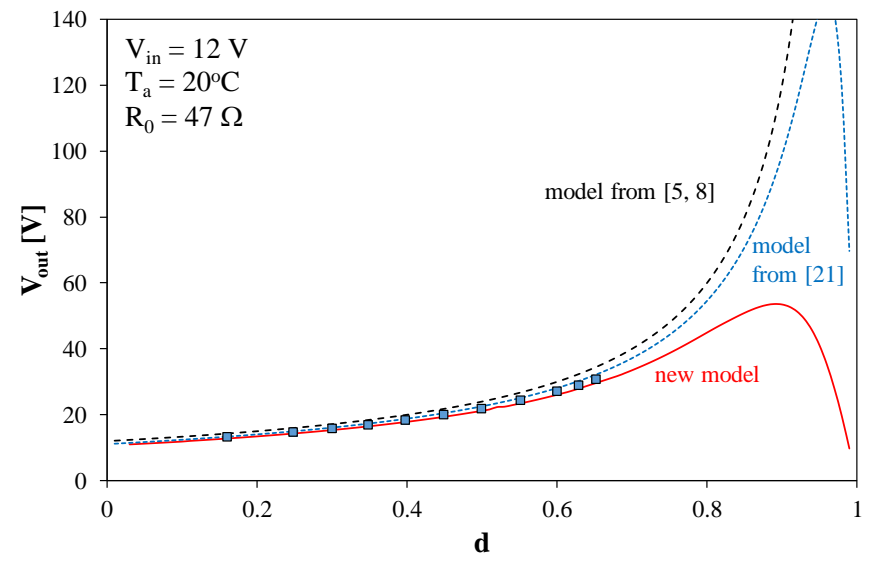

Figure 12. Computed and measured dependences of boost converter output voltage on duty cycle.

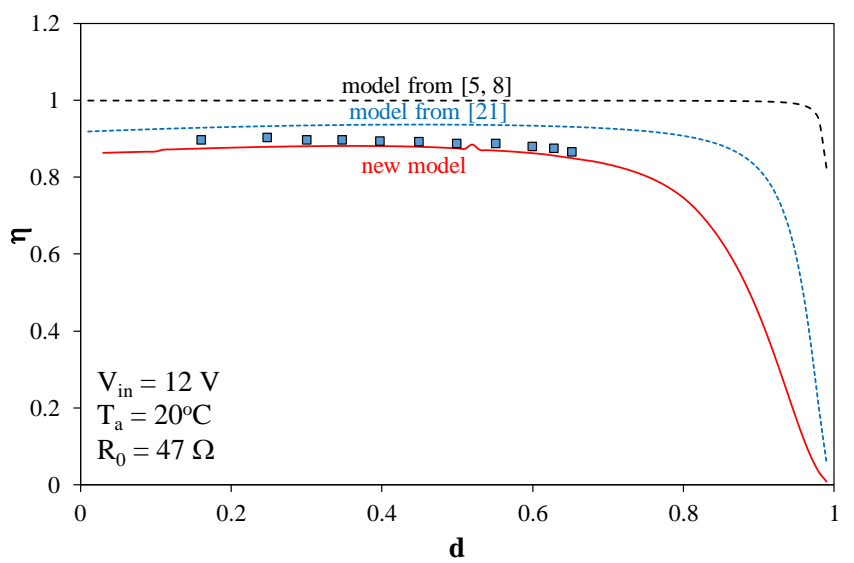

Figure 13. Computed and measured dependences of watt-hour efficiency of boost converter on duty cycle. 


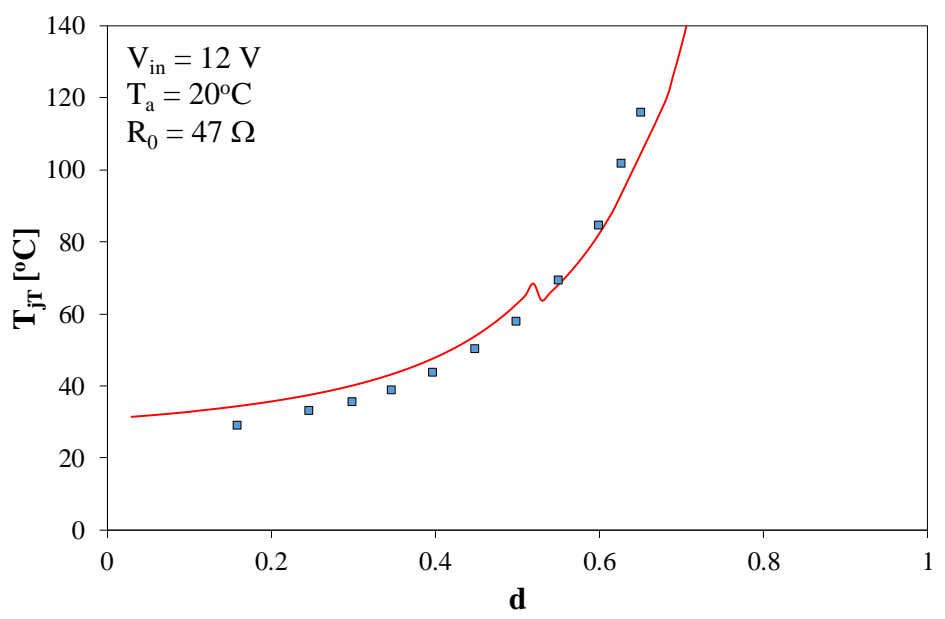

Figure 14. Computed and measured dependences of internal temperature of IGBT on duty cycle.

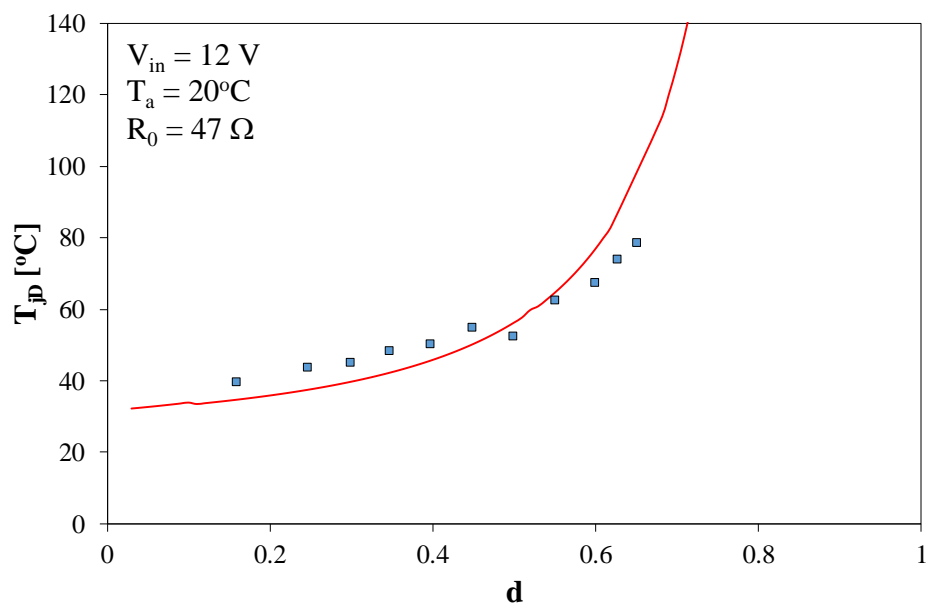

Figure 15. Computed and measured dependences of internal temperature of the diode on duty cycle.

As can be seen, very good accuracy in modeling this dependence was obtained only was CCM. In DCM differences between the results of measurements and computations increased with an increase in load resistance. They exceeded even $20{ }^{\circ} \mathrm{C}$ at $\mathrm{R}_{0}>6 \mathrm{k} \Omega$ which could be connected with a long switching-off process of IGBT [38], that was not taken into account in the proposed model.

In Figure 11 measured and computed (using the new model) dependence of internal temperature of diode on load resistance is shown.

The considered dependence is a monotonically decreasing function. The result of computations were convergent with the results of measurements. Differences did not exceed $4{ }^{\circ} \mathrm{C}$. Of course, the considered literature models did not make it possible to compute such dependence.

Figure 12 shows computed (with the new model) and measured dependences of converter output voltage on duty cycle.

In the whole considered range of changes of duty cycle the tested boost converter operated in $\mathrm{CCM}$. The measured dependence $\mathrm{V}_{\text {out }}(\mathrm{d})$ is a monotonically increasing function, but measurements were performed only for $\mathrm{d}<0.67$. The range of changes of $\mathrm{d}$ was limited due to a high increase in internal temperature of IGBT, which attained even $120^{\circ} \mathrm{C}$. The considered dependences computed using the electrothermal model and the model given in [21] had maxima at $\mathrm{d}>0.9$. These maxima were observed due to voltage drops on switched-on semiconductor devices [16]. It was also visible that due to self-heating the value of these maxima decrease even three times. Differences between the results of measurements and computations were small and they do not exceed $5 \%$.

Figure 13 illustrates dependence of watt-hour efficiency of the tested boost converter on duty cycle. 
As can be observed, dependences $\eta(d)$ were monotonically decreasing functions. The results of computations performed with the electrothermal model were convergent with the result of measurements. Differences do not exceed $2 \%$. Values of watt-hour efficiency computed using the other models were overstated even by $15 \%$.

Figure 14 presents measured and computed (with the new model) dependence of internal temperature of IGBT on duty cycle.

The considered dependence was an increasing function. The results of computations differ from the results of measurements not more than $5^{\circ} \mathrm{C}$.

Figure 15 shows measured and computed (with the new model) dependence of internal temperature of the diode on duty cycle.

It can be easily observed that temperature $\mathrm{T}_{\mathrm{j} D}$ increased with an increase in duty cycle. This means that the power dissipated in this diode increased, despite the fact that the time in which this diode was forward-biased decreased. The differences between the results of computations and measurements did not exceed a few degrees Celsius.

Figure 16 illustrates influence of duty-cycle on the output characteristics of the tested DC-DC converter (Figure 16a) and the dependence of diode internal temperature on the converter's output current $\mathrm{i}_{\text {out }}$.
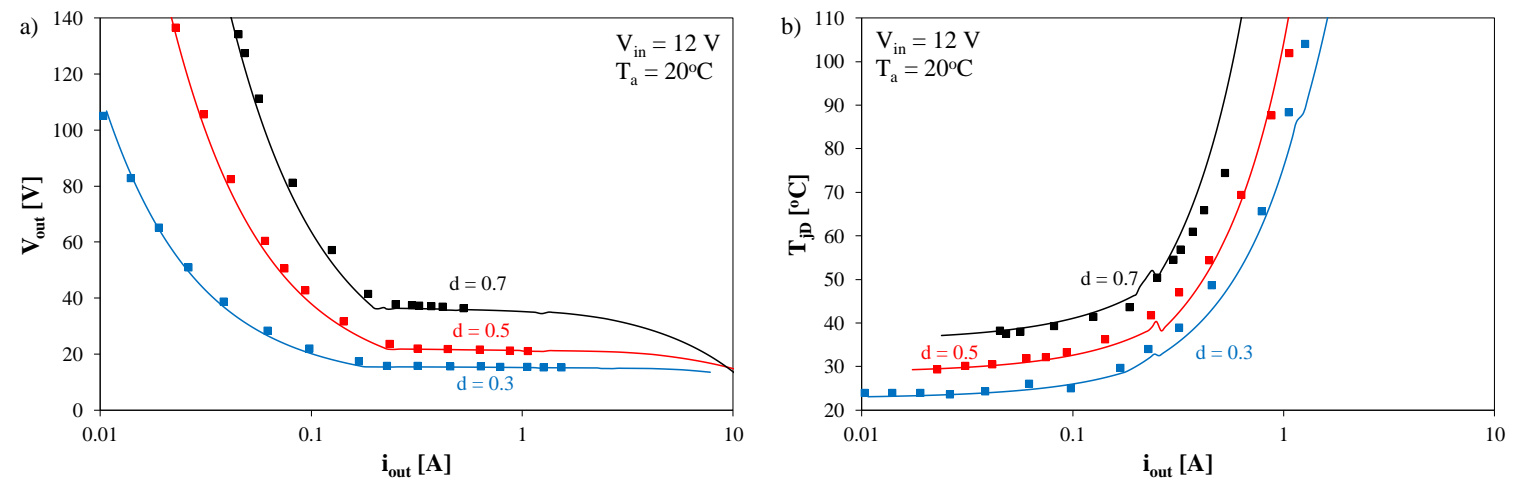

Figure 16. Computed and measured output characteristics of the tested DC-DC converter (a) and dependences of internal temperature of the diode on converter output current $(\mathbf{b})$ for selected values of duty cycle.

As it can be observed in Figure 16a, very good agreement between computed and measured output characteristics of the tested converter was obtained at all the considered values of duty cycle. The considered dependence was a decreasing function. The critical output current at which the mode of DC-DC converter operation change from DCM to CCM decreased with an increase in duty cycle $\mathrm{d}$. In turn, in Figure $16 \mathrm{~b}$, it can be observed that the dependence $\mathrm{T}_{\mathrm{jD}}\left(\mathrm{i}_{\text {out }}\right)$ was an increasing function and values of temperature $\mathrm{T}_{\mathrm{j}}$ increase with an increase in duty cycle.

An influence of ambient temperature on characteristics of the tested boost converter is illustrated in Figure 17.

It is clearly visible in Figure 17a that changes in value of ambient temperature practically do not influence value of output voltage of the tested boost converter. Points marking results of measurements performed in both the values of ambient temperature practically overlap as well as lines representing computations performed for these values of $\mathrm{T}_{\mathrm{a}}$. Changes in value of $\mathrm{V}_{\text {out }}$ voltage caused by change in ambient temperature did not exceed $0.3 \mathrm{~V}$. Hence, small value of these changes was a result of weak influence of temperature on IGBT output voltage. The same result were obtained during computations and measurements. In contrast, in Figure 17b, it is visible that change in the value of ambient temperature caused practically the same change in the value of internal temperature of the diode. The same influence of ambient temperature the Authors observed also for internal temperature of IGBT. 
Some additional computations of the tested boost converter were performed using the worked-out electrothermal averaged model of a diode transistor switch, including the IGBT and a rapid switching diode. For example, Figure 18 illustrated influence of load resistance on dependences of converter output voltage (Figure 18a) and internal temperature of the diode (Figure 18b) on the duty cycle.
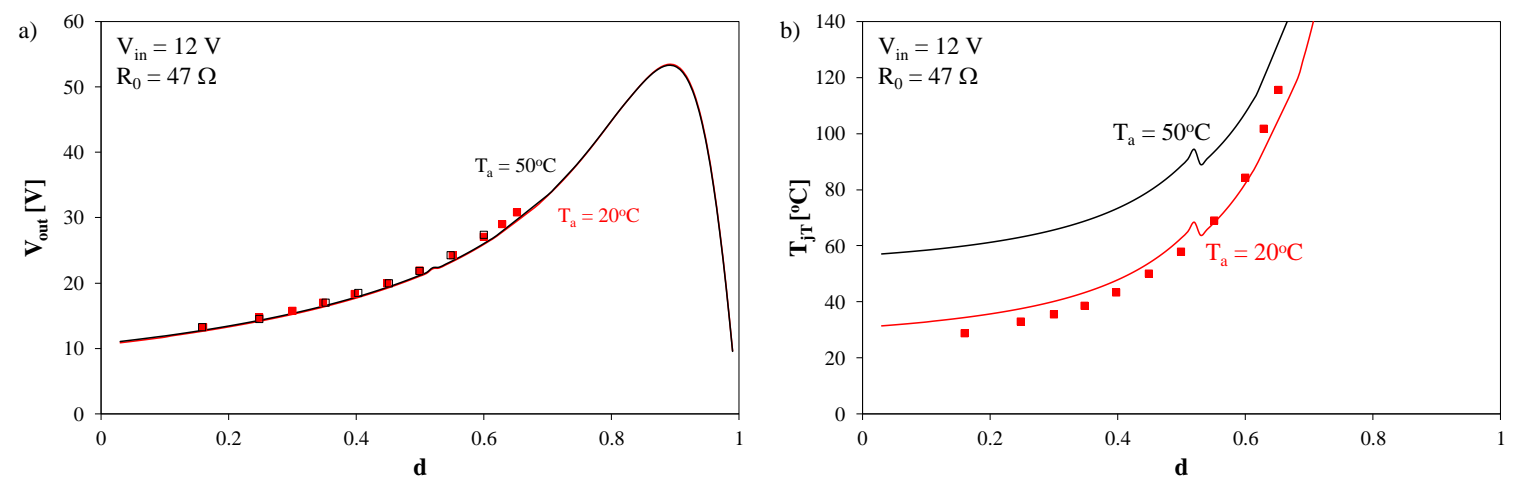

Figure 17. Computed and measured dependences of converter output voltage (a) and internal temperature of the diode $(\mathbf{b})$ on duty cycle.
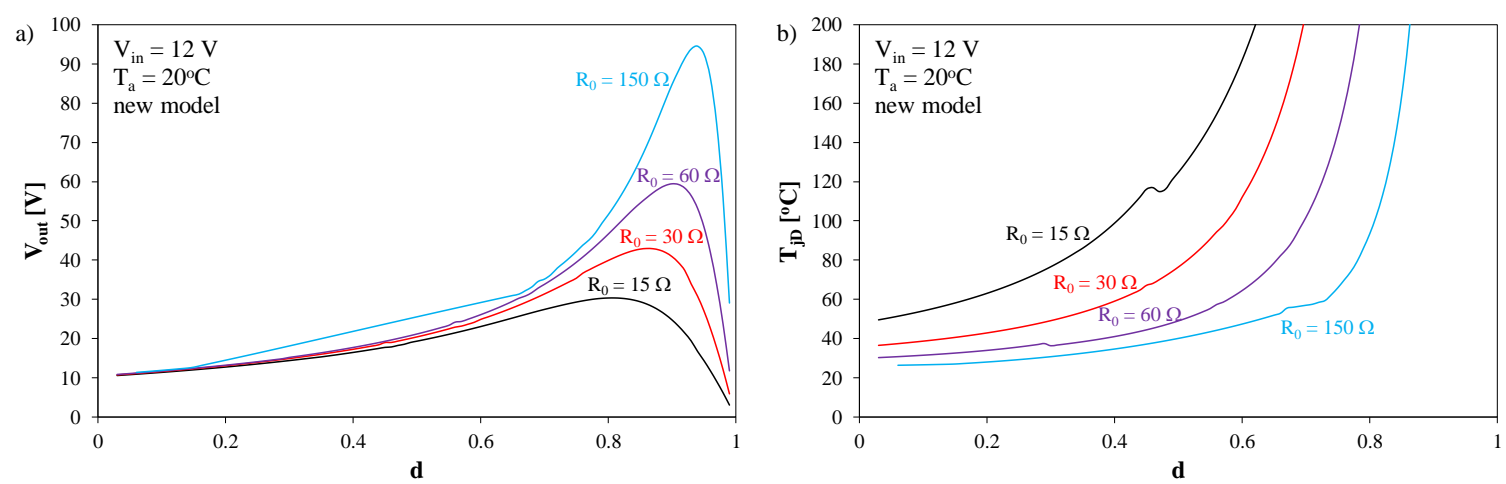

Figure 18. Computed dependences of converter output voltage (a) and internal temperature of the diode (b) on duty cycle for selected values of load resistance.

As it can be observed, an increase of load resistance $R_{0}$ caused an increase in the maximum value of converter output voltage and an increase in the value of duty cycle, at which the maximum in characteristic $\mathrm{V}_{\text {out }}(\mathrm{d})$ was observed. The maximum value of $\mathrm{V}_{\text {out }}$ voltage changes in the range from 30 to $94 \mathrm{~V}$. In turn, internal temperature of the diode was an increasing function of duty cycle and a decreasing function of load resistance. It is worth noticing that at the considered cooling conditions of the diode the acceptable value of duty cycle was strongly limited. For the considered values of $R_{0}$ the maximum value of duty cycle increased from about 0.5 (for $R_{0}=15 \Omega$ ) to about 0.8 (for $R_{0}=150 \Omega$ ).

Figure 19 illustrates the influence of duty cycle on dependences of converter output voltage (Figure 19a) and internal temperature of IGBT (Figure 19b) on load resistance.

In Figure $19 \mathrm{a}$ it is visible that dependence $\mathrm{V}_{\text {out }}\left(\mathrm{R}_{0}\right)$ was an increasing function for all considered values of duty cycle $\mathrm{d}$. It could also be observed that the value of load resistance at which the border between the CCM and DCM exists moves right with an increase in the value of $\mathrm{d}$. In CCM influence of energy losses in semiconductor devices on converter output voltage were much more visible for the highest value of duty cycle. In turn, in Figure 19b it can be seen that internal temperature of IGBT is a decreasing function of load resistance and an increasing function of duty cycle. Cooling conditions of IGBT limit the lowest admissible value of load resistance at the adjusted duty cycle. In the considered case for $d=0.8$ load resistance should not be smaller than $100 \Omega$ in order to limit the value of internal temperature of IGBT to $150{ }^{\circ} \mathrm{C}$. 

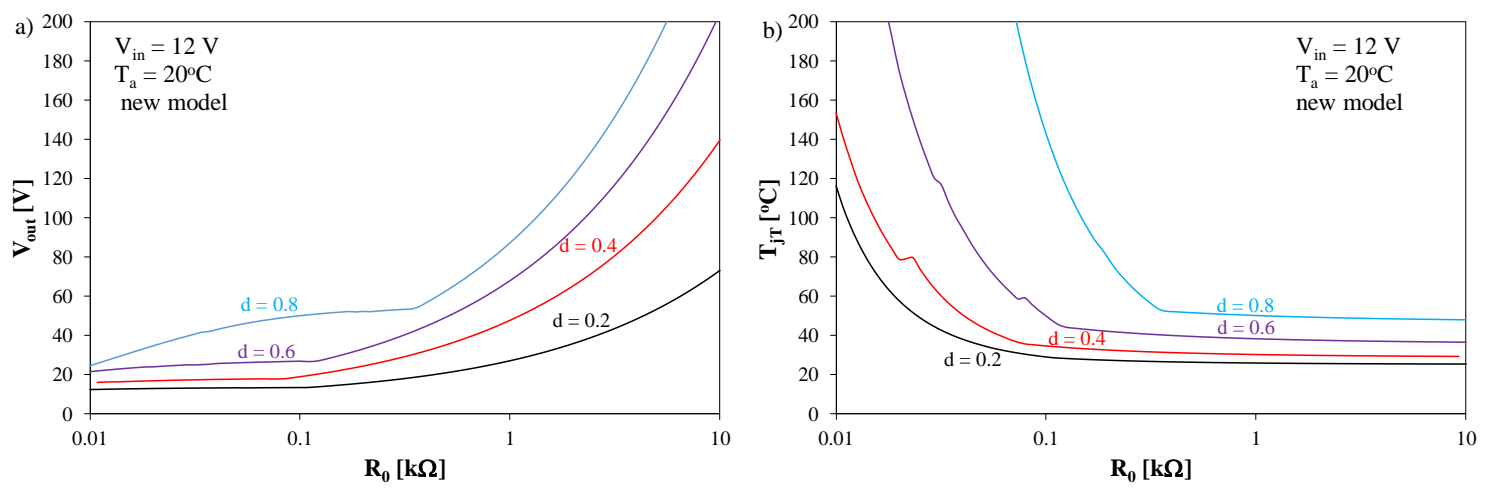

Figure 19. Computed dependences of converter output voltage (a) and internal temperature of IGBT (b) on load resistance for selected values of duty cycle.

\section{Conclusions}

In this study, a new electrothermal averaged model of the diode transistor switch-including IGBT and a rapid switching diode-is proposed. This model makes it possible to compute non-isothermal (taking into account self-heating phenomena) characteristics of DC-DC converters operating both in CCM and DCM. Values of voltages, currents and internal temperatures of semiconductor devices at the thermally steady state can be computed using this model. The proposed model uses piecewise linear approximation of current-voltage characteristics of IGBT and the diode operating in on-state.

Practical usefulness of the proposed model was verified for the boost converter operating both in CCM and DCM at different values of duty cycle of the control signal in a wide range of load resistance. It was shown that the new electrothermal averaged model makes it possible to obtain good accuracy of modeling dependences $V_{\text {out }}(d), V_{\text {out }}\left(R_{0}\right), \eta\left(R_{0}\right), \eta(d)$ and $V_{\text {out }}\left(i_{\text {out }}\right)$ in both operating modes of the converter. This accuracy is much higher than accuracy obtained with the use of the considered literature models, particularly in DCM.

The proposed model makes it also possible to compute values of internal temperature of both semiconductor devices operating in the tested DC-DC converter. The obtained results of computations of internal temperature of the diode are convergent with the results of measurements in all considered modes of operation of the DC-DC converter. In contrast, the results of computations of internal temperature of the IGBT fit well the results of measurements only for the DC-DC converter operating in CCM. In DCM, these differences can exceed even $20^{\circ} \mathrm{C}$. It was also shown that changes in the value of ambient temperature practically do not influence on the DC-DC converter operating at fixed values of duty cycle and load resistance. These changes cause changes in internal temperatures of IGBT and the diode. These changes are very important from the point of view of estimation life time of the tested converter. As it is known from the literature [39], an increase in value of device internal temperature by $8^{\circ} \mathrm{C}$ causes even twice decrease in life time of such devices.

Computations performed with the use of the proposed model illustrate influence of load resistance and duty-cycle of the control signal on selected characteristics of the boost converter. The obtained results of computations make it possible to estimate the range of admissible values of the mentioned parameters, for which internal temperature of the diode and IGBT does not exceed the admissible value given by the producer.

In further investigations, the authors will attempt to find a cause of these differences and will propose some modifications of the model. The model will be also tested in a wide range of frequency of the control signal and for different cooling conditions of semiconductor devices operating in the DC-DC converter, as well as at different values of input voltage, load current and ambient temperature.

Author Contributions: Conceptualization (P.G. and K.G.); computations (P.G. and K.G.), methodology (P.G. and K.G.); experimental verification (P.G.); writing text of the article (K.G. and P.G.); review and editing (K.G. and P.G.); visualization (P.G. and K.G.); supervision (K.G.). All authors have read and agreed to the published version of the manuscript. 
Funding: The scientific work is a result of the project No. 2018/31/N/ST7/01,818 financed by the Polish National Science Center.

Conflicts of Interest: The authors declare no conflicts of interest.

\section{References}

1. Rashid, M.H. Power Electronic Handbook; Academic Press: Cambridge, MA, USA; Elsevier: Amsterdam, The Netherlands, 2007.

2. Kazimierczuk, M. Pulse-Width Modulated DC-DC Power Converters; Wiley: Hoboken, NJ, USA, 2015.

3. Billings, K.; Morey, T. Switch-Mode Power Supply Handbook; McGraw-Hill Companies: New York, NY, USA, 2011.

4. Ang, S.; Oliva, A. Power-Switching Converters; CRC Press Taylor and Francis Group: Boca Raton, FL, USA, 2011.

5. Ericson, R.; Maksimovic, D. Fundamentals of Power Electronics; Kluwer Academic Publisher: Norwell, MA, USA, 2001.

6. Rashid, M.H. Spice for Power Electronics and Electric Power; CRC Press: Boca Raton, FL, USA, 2006.

7. Wells, B.A.; Brodlo, B.T.; Babaa, I.M.H. Analog computer simulation of a Dc-to-Dc flyback converter. IEEE Trans. Aerosp. Electron. Syst. 1967, AES-3, 399-409.

8. Basso, C. Switch-Mode Power Supply SPICE Cookbook; McGraw-Hill: New York, NY, USA, 2001.

9. Vladirmirescu, A. Shaping the History of SPICE. IEEE Solid-State Circuits Mag. 2011, 3, 36-39.

10. Maksimovic, D.; Stankovic, A.M.; Thottuvelil, V.J.; Verghese, G.C. Modeling and simulation of power electronics converters. Proc. IEEE 2001, 89, 898-912. [CrossRef]

11. Górecki, K.; Zarębski, J. The Method of a Fast Electrothermal Transient Analysis of Single-Inductance DC-DC Converters. IEEE Trans. Power Electron. 2012, 27, 4005-4012. [CrossRef]

12. Vorperian, V. Fast Analitycal Techniques for Electrical and Electronic Circuits; Cambridge University Press: Cambridge, UK, 2002.

13. Bedrosian, D.; Vlach, J. Time-domain analysis of networks with internally controlled switches. IEEE Trans. Circuits Syst. I Fund. Theory Appl. 1992, 39, 199-212. [CrossRef]

14. Ben-Yaakov, S.; Gaaton, Z. Generic SPICE compatible model of current feedback in switch mode convertors. Electron. Lett. 1992, 28, 1356-1358. [CrossRef]

15. Ben-Yaakov, S.; Glozman, S.; Rabinovici, R. Envelope simulation by SPICE-compatible models of electric circuits driven by modulated signals. IEEE Trans. Ind. Electron. 2000, 47, 222-225. [CrossRef]

16. Górecki, K. A new electrothermal average model of the diode-transistor switch. Microelectron. Reliab. 2008, 48, 51-58. [CrossRef]

17. Górecki, K.; Detka, K. Application of Average Electrothermal Models in the SPICE-Aided Analysis of Boost Converters. IEEE Trans. Ind. Electron. 2019, 66, 2746-2755. [CrossRef]

18. Pavlovic, T.; Bjazic, T.; Ban, Z. Simplified Averaged Models of DC-DC Power Converters Suitable for Controller Design and Microgrid Simulation. IEEE Trans. Power Electron. 2013, 28, 3266-3275. [CrossRef]

19. Meo, S.; Toscano, L. Some New Results on the Averaging Theory Approach for the Analysis of Power Electronic Converters. IEEE Trans. Ind. Electron. 2018, 65, 9367-9377. [CrossRef]

20. Han, J.; Zhang, B.; Qiu, D. Bi-switching Status Modeling Method for DC-DC Converters in CCM and DCM Operations. IEEE Trans. Power Electron. 2017, 21, 2464-2472. [CrossRef]

21. Górecki, P. Application of the averaged model of the diode-transistor switch for modelling characteristics of a boost converter with an IGBT. Int. J. Electron. Telecommun. 2020. in review.

22. Bryant, A.; Allotey, N.A.P.; Hamilton, D.; Swan, I.; Mawby, P.; Ueta, T.; Nishijima, T.; Hamada, K. A Fast Loss and Temperature Simulation Method for Power Converters, Part I: Electrothermal Modeling and Validation. IEEE Trans. Power Electron. 2012, 27, 248-257. [CrossRef]

23. Górecki, K.; Zarębski, J. Modeling nonisothermal characteristics of switch-mode voltage regulators. IEEE Trans. Power Electron. 2008, 23, 1848-1858. [CrossRef]

24. Górecki, K. Non-linear average electrothermal models of buck and boost converters for SPICE. Microelectron. Reliab. 2009, 49, 431-437. [CrossRef]

25. Bryant, B.; Kazimierczuk, M.K. Voltage-Loop Power-Stage Transfer Functions with MOSFET Delay for Boost PWM Converter Operating in CCM. IEEE Trans. Ind. Electron. 2007, 54, 347-353. [CrossRef] 
26. Starzak, Ł.; Zubert, M.; Janicki, M.; Torzewicz, T.; Napieralska, M.; Jabłoński, G.; Napieralski, A. Behavioral approach to SiC MPS diode electrothermal model generation. IEEE Trans. Electron Devices 2013, 60, 630-638. [CrossRef]

27. Mawby, P.A.; Igic, P.M.; Towers, M.S. Physically based compact device models for circuit modelling applications. Microelectron. J. 2001, 32, 433-447. [CrossRef]

28. Wilamowski, B.M.; Jaeger, R.C. Computerized Circuit Analysis Using SPICE Programs; McGraw-Hill: New York, NY, USA, 1997.

29. IGP06N60T, Datasheet, Infineon Technologies. Available online: https://www.infineon.com/dgdl/InfineonIGP06N60T-DS-v02_03-en.pdf?fileId=db3a30432313ff5e0123b82d13ba7883 (accessed on 7 April 2020).

30. IDP08E65D1, Datasheet, Infineon Technologies. Available online: https://www.alldatasheet.com/datasheetpdf/pdf/756371/INFINEON/IDP08E65D1.html (accessed on 7 April 2020).

31. Measuring HEXFET Characteristics, Application Note AN-957, International Rectifier. Available online: https: //www.infineon.com/dgdl/an-957.pdf?fileId=5546d462533600a40153559f0dfc11dc (accessed on 7 April 2020).

32. Keithley 2612a, Datasheet. Available online: http://www.testequipmenthq.com/datasheets/KEITHLEY2612A-Datasheet.pdf (accessed on 11 June 2020).

33. Górecki, P.; Górecki, K. Influence of thermal phenomena on dc characteristics of the IGBT. Int. J. Electron. Telecommun. 2018, 64, 71-76.

34. Górecki, K.; Górecki, P.; Zarębski, J. Measurements of parameters of the thermal model of the IGBT module. IEEE Trans. Instrum. Meas. 2019, 68, 4864-4875. [CrossRef]

35. Blackburn, D.L. Temperature Measurements of Semiconductor Devices-A Review. In Proceedings of the 20th IEEE Semiconductor Thermal Measurement and Menagement Symposium SEMI-THERM, San Jose, CA, USA, 11 March 2004; pp. 70-80.

36. Górecki, K.; Zarębski, J. Modeling the influence of selected factors on thermal resistance of semiconductor devices. IEEE Trans. Compon. Packag. Manuf. Technol. 2014, 4, 421-428. [CrossRef]

37. Pyrometer PT-3S, Optex Product Information. Available online: http://www.dewetron.cz/optex/katlisty/PT3S.pdf (accessed on 11 June 2020).

38. Górecki, P.; Górecki, K. Modelling a Switching Process of IGBTs with Influence of Temperature Taken into Account. Energies 2019, 12, 1894. [CrossRef]

39. Narendran, N.; Gu, Y. Life of LED-based white light sources. J. Disp. Technol. 2005, 1, 167-171. [CrossRef]

(C) 2020 by the authors. Licensee MDPI, Basel, Switzerland. This article is an open access article distributed under the terms and conditions of the Creative Commons Attribution (CC BY) license (http://creativecommons.org/licenses/by/4.0/). 